\title{
BOND STRENGTH AND INTERFACIAL MORPHOLOGY OF A MULTI- MODE ADHESIVE RESIN CEMENT TO ENAMEL AND DENTIN
}

\begin{abstract}
Holiel $\mathbf{A}^{\mathbf{1}} B D S$, Abdel-Fattah $\mathbf{W}^{\mathbf{2}} P h D$, El Mallakh $\mathbf{B}^{\mathbf{3}} P h D$.
Abstract:

Introduction: Resin cements are used for cementation of indirect restorations. A high-quality adhesion to tooth structure is primordial for the success of indirect cemented restorations.

Objectives: Were to assess the shear bond strength of RelyX ultimate adhesive resin cement to both enamel and dentin when used in different application modes (self-etch and total-etch) and to study resin-tooth interfaces using SEM.

Materials and methods: 40 enamel specimens and 40 dentin specimens were used in this study. Each substrate specimens were randomly divided into four groups of 10 specimens each according to resin cement applied: Enamel groups: Group A1: RelyX ultimate as total-etch; Group A2: RelyX ultimate as self-etch; Group A3: Variolink II; Group A4: Multilink automix. Dentin groups: Group B1: RelyX ultimate as total-etch; Group B2: RelyX ultimate as self-etch; Group B3: Variolink II; Group B4: Multilink automix. Resin cements were built over the surfaces following manufacturer's instructions in a plastic tube. All specimens were thermocycled $\left(500\right.$ cycles, $5^{\circ} / 55^{\circ} \mathrm{C}, 15$ sec dwell time) then shear bond strength was measured in MPa and data were analyzed using F-test (ANOVA) and Post Hoc test. Three specimens from each group were further sectioned, gold sputtered and evaluated under SEM.

Results: All enamel groups showed a statistically significant difference for shear bond strength with $\mathrm{P}<0.001$. Group A1 revealed the highest mean value of $35.60 \mathrm{MPa}$. While for dentin, there was no statistically significant differences among groups with $\mathrm{P}=0.053$. Interfacial morphology of RelyX ultimate in total-etch mode showed better interface morphology and improved tag length compared to respective self-etch counterpart Conclusions: An etching step prior to multi-mode adhesive resin cement increased its bond strength values and improved its penetration pattern to both enamel and dentin, also length of resin tags formed by total-etch adhesives seems not to play an important role in determining bond strength

Keywords: Resin cements, Adhesives, Multi-mode, dental substrates, bonding, interface.

1- Instructor at the Conservative Dentistry Department, Faculty of Dentistry, Alexandria University, Egypt.

2 - Professor of Conservative Dentistry, Faculty of Dentistry, Alexandria University, Egypt.

3 - Professor of Dental Biomaterials, Faculty of Dentistry, Alexandria University, Egypt.
\end{abstract}

\section{INTRODUCTION}

Tooth colored inlays, onlays, veneers and crowns are now routinely bonded to the tooth substrate via the use of adhesive resin cements as they have the ability to bond to both tooth structure and restoration. The integration reinforces both structures and reduces microleakage at the restoration-tooth interface, postoperative sensitivity, marginal staining and recurrent caries (1). A durable bond at the tooth-restoration interface is fundamental for longterm success of an adhesive restoration (2). An extremely relevant factor for the success of cementation is the type of adhesive used together with the cement because the former is responsible for the bonding between the tooth structure and the cement itself (3).

Traditional resin cements can be divided into two groups according to the adhesive system used to prepare the tooth prior to cementation. One group utilizes etch-and-rinse adhesive systems (two -or three-step), whereas for the other group, dental substrates are prepared using self-etch primers/adhesives (one- and two-step) (4).

The total-etch strategy requires previous acid etching of the enamel and dentin surfaces which leads to the formation of pores and permits mechanical interlocking to the enamel, and exposition of collagen fiber network of dentin, resulting in the formation of hybrid layer. However, this technique consists of several clinical steps that have to be rigorously followed, a fact that makes this method complex and time consuming (5). In addition, the possibility of over etching the dentin and the difficulty in clinically determining the ideal moisture point of the etched substrate may result in the presence of dentinal collagen exposed by the acid but not impregnated by the adhesive, affecting bond durability (6).

The self-etch strategy depends on acid monomers that etch the substrate and simultaneously fill the pores formed, so they reduce the working time and speed up the cementation process of indirect restorations. In addition the mild etching provided by these agents might be more favorable since it does not completely remove the smear plugs present in the tubules, thus preventing an increase in dentinal permeability and reducing the chance of postoperative sensitivity (7). However, there are conflicting reports regarding the enamel bond strengths of indirect restorations using self-etch cements as the acidity of non-rinsed acidic primers may negatively affect the bond strength to enamel (8).

The use of phosphoric acid before the application of nonrinsed adhesives or self-adhesive cements has been suggested to improve adhesion. The efficacy of enamel acid pretreatment has been questioned (9). also the effect of intentionally etching dentin prior to the application of selfetch adhesives has been studied with controversial results $(10,11)$.

Considering the differences in professional judgment regarding the selection of the adhesive strategy and number of steps, some manufacturers have released more versatile adhesive systems that include etch-and-rinse and self-etch 
options. These new materials are called universal or multimode adhesives (12-14).

Combining a universal multi-mode adhesive with a new resin cement gives it the versatility to cover all techniques and all indications as the cement can be used either in a self-etch mode or in a total-etch mode (15). The aim of the present in vitro study was to determine the performance of a new multi-mode adhesive resin cement when bonded to enamel and dentin in the different application modes and to assess the morphological characterization of the tooth/adhesive interface microscopically. The null hypothesis advanced in the study was that prior etching of enamel and dentin with phosphoric acid does not influence the bonding efficiency of multi-mode adhesive system.

\section{MATERIALS AND METHODS}

Forty extracted human permanent anterior teeth for shear bond strength of resin cements to enamel and 40 extracted human permanent molar teeth for shear bond strength of resin cements to dentin were used in this study. Selected teeth were free of caries, attrition, abrasion, cracking or previous restoration. The teeth were thoroughly washed with tap water, debrided from all soft tissues or bone, and stored in physiological saline at room temperature until use. Three resin cements with their respective adhesives were used in this study: RelyX ultimate (3MESPE, St.Paul, MN, USA), Variolink II and Multilink automix (Ivoclar Vivadent, Schaan, Liechtenstein) as shown in (Table 1).

Anterior teeth had their labial surface ground flat under running water using a diamond stone mounted to a high speed handpiece. Molar teeth had their occlusal surface ground flat by means of a mechanical grinder to remove enamel and expose flat dentinal surfaces, then the flattened surfaces were polished using \#600 grit silicon carbide paper under running water. Roots were cut just cervical to the cemento-enamel junction with a diamond disc mounted on a low speed handpiece

Split-copper metallic molds of $20 \mathrm{~mm}$ length and $14 \mathrm{~mm}$ diameter were filled with auto polymerizing acrylic resin. The enamel specimens were embedded into the acrylic resin with their labial surface facing upwards, while the dentin specimens were embedded with their occlusal surface facing upwards. Each substrate specimens were then divided into four groups of ten specimens eachaccording to resin cement applied

Enamel groups: Group A1: RelyX ultimate in total-etch mode; Group A2: RelyX ultimate in self-etch mode; Group A3: Variolink II (total-etch); Group A4: Multilink automix (self-etch).

Dentin groups: Group B1:RelyX ultimate in total-etch mode; Group B2:RelyX ultimate in self-etch mode; Group B3:Variolink II (total-etch); Group B4: Multilink automix (self-etch). A thin walled plastic tube (3.5 $\mathrm{mm}$ diameter and $2 \mathrm{~mm}$ height) was carefully centered on the flat tooth surface and secured in position with sticky wax.The resin cements were applied inside the tube following strictly the manufacturer instructions (Table 1).

Enamel and dentinspecimenswere stored in distilled water at $37{ }^{\circ} \mathrm{C}$ for $24 \mathrm{~h}$ and were then thermocycled 500 cycles between $5{ }^{\circ} \mathrm{C}$ and $55{ }^{\circ} \mathrm{C}$ with a dwell time of 15 seconds at each temperature (16). All specimens were then subjected to shear bond strength test using a universal testing machine

Table (1): List of material composition and application procedures

\begin{tabular}{|c|c|c|}
\hline Material & Composition & Application procedures \\
\hline $\begin{array}{l}\text { RelyX Ultimate } \\
\text { resin cement }\end{array}$ & $\begin{array}{l}\text { Base Paste: Methacrylate monomers, Radiopaque silanated } \\
\text { fillers, Initiator components, Stabilizers, Rheological additives } \\
\text { Catalyst Paste: Methacrylate monomers, Radiopaque alkaline } \\
\text { (basic) fillers, Initiator components, Stabilizers, Pigments } \\
\text { Rheological additives, Fluorescence dye, Dark cure activator for } \\
\text { Scotch bond Universal adhesive. }\end{array}$ & \multirow{3}{*}{$\begin{array}{l}\text { Self-etch mode: } \\
\text { 1. Apply Scotchbond universal adhesive with brush } \\
\text { and rub for } 20 \mathrm{~s} \text {, gently air dry for } 5 \mathrm{~s} \text { and light-cure } \\
\text { for } 10 \mathrm{~s} \text {. } \\
\text { 2. Dispense cement from the automix double-push } \\
\text { syringe and light cure for } 20 \mathrm{~s} \text {. } \\
\text { Total-etch mode: } \\
\text { 1. Apply Scotchbond Etchant for } 15 \mathrm{~s} \text {, rinse with } \\
\text { water for } 10 \mathrm{~s} \text { and then dry with cotton pellets. } \\
\text { 2. Apply Scotchbond adhesive with brush and rub } \\
\text { for } 20 \mathrm{~s} \text {, gently air dry for } 5 \mathrm{~s} \text { and light-cure for } 10 \mathrm{~s} \\
\text { 3. Dispense cement from the automix double-push } \\
\text { syringe and light cure for } 20 \mathrm{~s} \text {. }\end{array}$} \\
\hline $\begin{array}{l}\text { scotchbond } \\
\text { Universal } \\
\text { Adhesive }\end{array}$ & $\begin{array}{l}\text { MDP Phosphate Monomer, Dimethacrylate resins, HEMA, } \\
\text { polyalkenoic acid Copolymer, Filler, Ethanol, Water, Initiators, } \\
\text { Silane. }\end{array}$ & \\
\hline $\begin{array}{l}\text { Scotch bond } \\
\text { Universal Etchant }\end{array}$ & th a $\mathrm{pH}$ of approximately 0.1 colloidal & \\
\hline $\begin{array}{l}\text { Variolink II resin } \\
\text { cement }\end{array}$ & $\begin{array}{l}\text { BisGMA, UDMA, TEGDMA, barium glass fillers, ytterbium } \\
\text { trifluoride, boroalumino fluorosilicate glass, spheroidal mixed } \\
\text { oxide, catalysts, stabilizers, pigments. }\end{array}$ & \multirow{3}{*}{$\begin{array}{l}\text { 1. Apply total-etch phosphoric acid }(37 \%) \text { for } 30 \mathrm{~s} \\
\text { on enamel and } 15 \mathrm{~s} \text { on dentin, rinse for } 10 \mathrm{~s} \text { and } \\
\text { blot-dry with cotton pellet. } \\
2 \text {. Apply Excite DSC with a brush and agitate } 10 \mathrm{~s} \text {, } \\
\text { dry for } 1-3 \mathrm{~s} \text { and then light-cure for } 20 \mathrm{~s} \text {. } \\
3 . \text { Dispense cement catalyst and base on a mixing } \\
\text { pad and mix in a } 1: 1 \text { ratio and apply into the plastic } \\
\text { tube and light cure for } 20 \mathrm{~s} \text {. }\end{array}$} \\
\hline Excite Dsc & $\begin{array}{l}\text { DMA, HEMA, alcohol, phosphoric acid acrylate, } \mathrm{SiO} 2 \text {, initiators, } \\
\text { stabilizers }\end{array}$ & \\
\hline Etchan & ickening agent and colorants. & \\
\hline $\begin{array}{l}\text { Multilink automix } \\
\text { resin cement }\end{array}$ & $\begin{array}{l}\text { Multilink Base and Catalyst: Bis-EMA, UDMA, bis-GMA, } \\
\text { HEMA, barium glass filler, silicon dioxide filler, ytterbium } \\
\text { trifluoride, catalysts, stabilizers, pigments }\end{array}$ & \multirow{2}{*}{$\begin{array}{l}\text { 1. Mix Multilink Primers A and B in } 1: 1 \text { ratio. } \\
\text { 2. Scrub mixed primer on surface with brush for } 30 \\
\text { s on enamel and } 15 \mathrm{~s} \text { on dentin. } \\
\text { 3. Applied primer is subsequently dried with water- } \\
\text { and oil-free air. } \\
\text { 4. Dispense Multilink cement from automix double- } \\
\text { push syringe then light cure for } 20 \mathrm{~s} \text {. }\end{array}$} \\
\hline $\begin{array}{c}\text { Multilink } \\
\text { Primer A / B }\end{array}$ & $\begin{array}{l}\text { Multilink Primer A is an aqueous solution of initiators. } \\
\text { Multilink Primer B contains HEMA, phosphonic acid and } \\
\text { methacrylate monomers }\end{array}$ & \\
\hline
\end{tabular}


(Comten Industries, INC., Florida, USA) with the stainless steel knife perpendicular to the junction between the tooth surface and the resin cement at a cross head $0.5 \mathrm{~mm} /$ minute until failure occurred. The fracture load was recorded and the shear bond strength was calculated in MPa. Comparison of mean values of shear bond strength between the studied groups of enamel and dentin and was done using F-test (ANOVA) and Post Hoc test (Tukey). Significance level was set at the $5 \%$ level.

For observation of the Interfacial morphology, three specimens from each group were further longitudinally sectioned in a mesio-distal direction to expose the resintooth interface using a diamond disc at low speed handpiece under water coolant. The exposed surfaces were air-dried and smoothed with increasingly finer grit silicon carbide papers (\#600, \#1000, \#1500, \#2000) under running water. They were then etched with $37 \%$ phosphoric acid solution for 10 seconds to remove the mineral content, washed with water and immersed in 5\% sodium hypochlorite for $5 \mathrm{~min}$ to remove exposed collagen for better observation of resin tags. Finally, specimens were subjected to ultrasonic bath with distillated water for $10 \mathrm{~min}$ and allowed to dry overnight and then gold sputtered and observed under SEM (JEOL JSM -5300 Scanning Microscope, Japan) at x3.500 magnification $(17,18)$.

\section{RESULTS}

In enamel, the difference in the mean values of shear bond strength ofthe four groups showed a statistically significant difference with $\mathrm{P}<0.001$. Group A1 and Group A3 showed the highest mean values $(35.60$ and $32.60 \mathrm{MPa}$ respectively). Group A2 and Group A4 showed no statistically significant difference with mean values of (25.69 and $23.78 \mathrm{MPa}$ respectively). Etching enamel revealed a statistically significant increase in the mean values of shear bond strength of RelyX ultimate cement with $\mathrm{P}<0.001$ (Table 2).

Table (2): Comparison between the different studied groups of enamel according to shear bond strength (MPa).

\begin{tabular}{|c|c|c|c|c|c|c|}
\hline & \multicolumn{4}{|c|}{ Enamel groups } & \multirow[b]{2}{*}{$\mathbf{F}$} & \multirow[b]{2}{*}{ p } \\
\hline & $\begin{array}{c}\text { A1 } \\
(\mathrm{n}=10)\end{array}$ & $\begin{array}{c}\mathbf{A 2} \\
(\mathrm{n}=10)\end{array}$ & $\begin{array}{c}\mathrm{A3} \\
(\mathrm{n}=10)\end{array}$ & $\begin{array}{c}\mathrm{A4} \\
(\mathrm{n}=10)\end{array}$ & & \\
\hline \begin{tabular}{|l} 
Shear bond \\
Strength \\
(MPa) \\
Min. - Max. \\
Mean \pm SD. \\
Median \\
\end{tabular} & $\begin{array}{c}32.80-39.70 \\
35.60 \pm 2.51 \\
35.2 \\
\end{array}$ & $\begin{array}{c}23.0-31.40 \\
26.69 \pm 2.82 \\
26.55 \\
\end{array}$ & $\begin{array}{c}30.55-38.15 \\
32.60 \pm 2.34 \\
31.88\end{array}$ & $\begin{array}{c}21.20-29.20 \\
23.78 \pm 2.37 \\
23.40\end{array}$ & $45.997^{*}$ & $<0.001$ \\
\hline $\mathrm{p}_{1}$ & & $<0.001^{\circ}$ & 0.053 & $<0.001^{*}$ & & \\
\hline$p_{2}$ & & & $<0.001^{\circ}$ & 0.064 & & \\
\hline $\mathrm{p}_{3}$ & & & & $<0.001^{\circ}$ & & \\
\hline
\end{tabular}

F: F test (ANOVA) *: Statistically sig. at $\mathrm{p} \leq 0.05$.

While for dentin, the difference in the mean values of shear bond strength of the four groups showed generally no statistically significant difference with $\mathrm{P}=0.053$. Mean values were (21.68 $\mathrm{MPa}, 19.72 \mathrm{MPa}, 20.73 \mathrm{MPa}$ and 18.64 MPa respectively). An etching step prior to RelyX ultimate cement resulted in a non-significantly increased bond strength with $\mathrm{P}=0.302$ (Table 3 ).
Table (3): Comparison between the different studied groups of dentin according to shear bond strength $(\mathrm{MPa})$.

\begin{tabular}{|c|c|c|c|c|c|c|}
\hline & \multicolumn{4}{|c|}{ Dentin groups } & \multirow[b]{2}{*}{$\mathbf{F}$} & \multirow[b]{2}{*}{ p } \\
\hline & $\begin{array}{c}\text { B1 } \\
(n=10)\end{array}$ & $\begin{array}{c}\text { B2 } \\
(n=10)\end{array}$ & $\begin{array}{c}\text { B3 } \\
(n=10)\end{array}$ & $\begin{array}{c}\text { B4 } \\
(n=10)\end{array}$ & & \\
\hline $\begin{array}{l}\text { Shear bond } \\
\text { Strength } \\
\text { (MPa) }\end{array}$ & & & & & & \\
\hline Min.-Max. & $18.80-26.40$ & $15.60-24.30$ & $17.80-25.40$ & $16.40-23.80$ & & \\
\hline $\begin{array}{c}\text { Mean } \pm \text { SD } \\
\text { Median }\end{array}$ & $\begin{array}{c}21.68 \pm 2.35 \\
21.40\end{array}$ & $\begin{array}{c}19.72 \pm 2.27 \\
19.50\end{array}$ & $\begin{array}{c}20.73 \pm 2.73 \\
20.20\end{array}$ & $\begin{array}{c}18.64 \pm 2.50 \\
17.85\end{array}$ & 2.809 & 0.053 \\
\hline$p_{1}$ & & 0.302 & 0.825 & $0.043^{\circ}$ & & \\
\hline $\mathrm{p}_{2}$ & & & 0.797 & 0.763 & & \\
\hline $\mathrm{p}_{3}$ & & & & 0.249 & & \\
\hline
\end{tabular}

$\mathrm{F}: \mathrm{F}$ test (ANOVA) *: Statistically sig. at $\mathrm{p} \leq 0.05$.

SEM micrographs of the resin-enamel interface from RelyX ultimate in total-etch mode showed thin resin tags penetrating into enamel. When applied in self-etch mode, there was absence of any penetrating resin tags and an evident hybrid layer was seen. Variolink II showed fewer and longer resin tags than RelyX ultimate in total-etch mode, while Multilink automix showed very thin, nonuniform hybrid layer with absence of any resin tags (Figure 1).

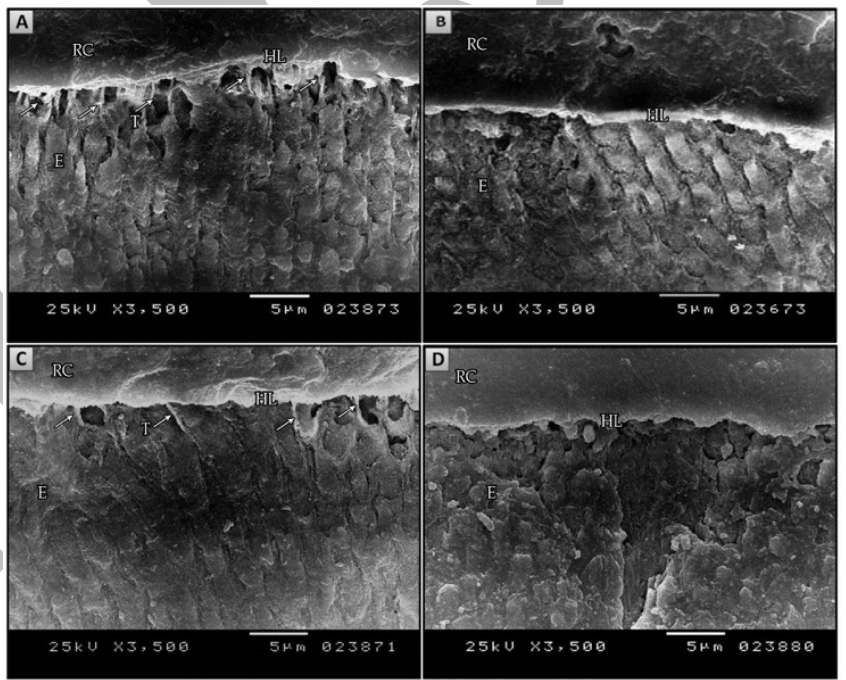

Fig.1: SEM micrographs of the resin-enamel interface formed by (A) RelyX ultimate resin cement in total-etch mode; (B) RelyX ultimate resin cement in self-etch mode; (C) Variolink II total-etch resin cement; (D) Multilink automix self-etch resin cement, x3500. RC: Resin cement, E: Enamel, HL: hybrid layer, $\mathrm{T}$ : Resin tags.

Resin-dentin interface showed that RelyX ultimate in total-etch mode was able to penetrate into dentin forming thicker hybrid layer with numerous, well-defined and deep resin tags. When applied in self-etch mode, very few resin tags with shallow penetration and thin uniform hybrid layer were seen. Variolink II showed variability in the length and less density of resin tags than RelyX ultimate as total-etch. Multilink automix showed thicker hybrid layer than RelyX ultimate as self-etch and few resin tags of variable shape with shallow penetration (Figure2). 


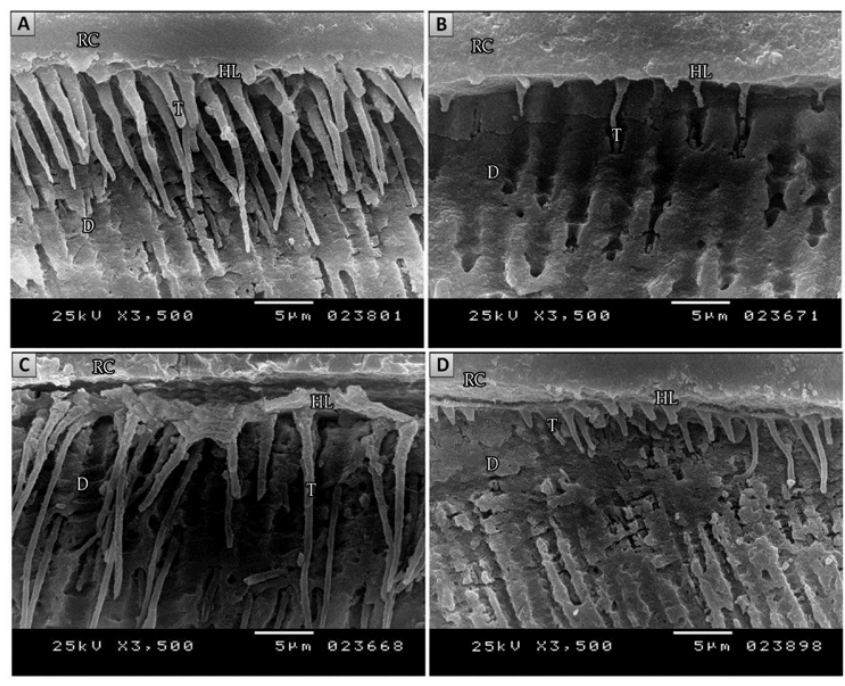

Fig.2: SEM micrographs of the resin-dentin interface formed by (A) RelyX ultimate resin cement in total-etch mode; (B) RelyX ultimate resin cement in self-etch mode; (C) Variolink II total-etch resin cement; (D) Multilink automix self-etch resin cement, x3500. RC: Resin cement, D: Dentin, HL: Hybrid layer, T: Resin tags.

\section{DISCUSSION}

The main challenge for dental adhesives is to provide an equally effective bond to two hard tissues of different nature. One of the most recent novelties in adhesive dentistry was the introduction of multi-mode adhesives that usually contain all bonding components in a single bottle and may be applied either in etch-and-rinse or self-etch bonding approaches (12).

In the present study the results of shear bond strength to enamel revealed that RelyX ultimate in total-etch mode and Variolink II total-etch resin cement had a significantly higher bond strength than Multilink automix self-etch resin cement, this comes in agreement with Hikita et al (3) and Inoue et al (5) who also reported higher enamel bond strengths when adhesive cements were combined with totaletch adhesives. These findings may be attributed to the demineralization capacity of the etching agents as studies have shown that when enamel was etched by phosphoric acid the adhesive system penetrates to a depth of $1 \mu \mathrm{m}$ between the enamel crystallites forming micromechanical interlocking through the formation of resin tags, whereas enamel etched by components of the self-etch adhesive the adhesive only reaches a depth of 0.6-0.7 $\mu \mathrm{m}$ and is based on an inter- and intra-crystallite hybridization of enamel surface $(19,20)$. Thus, the shallower etching pattern on enamel and subsequent reduced micro-mechanical retention might jeopardize bonding (21). The results of interfacial morphology in this study supported the bond-strength data, since more intimate micromechanical interlocking at the etched enamel surface could be achieved.

Furthermore, when enamel was etched prior to application of RelyX ultimate multi-mode adhesive cement, the results of the current study showed significant increase in the bond strength values and betterinterfacial morphology. Therefore, the null hypothesis that etching of enamel does not influence the bonding efficiency of multi-mode adhesive system was rejected. These results are in line with Erickson et al (22) and Li et al (23) who found improved bond strengths with a preetch step and attributed this to the degree of etching or the etch morphology achieved as etching increase the bonding area and the wettability of the adherent surface, promoting good micromechanical retention and increasing the bond strength values. However, Watanabe et al (24) stated that improvement in bond strengths after etching of enamel surfaces using phosphoric acid depends on the brand of the self-etch adhesive used, so not only the depth of enamel etching, but also the composition and mechanical properties of the self-etch adhesives might play important roles in determining bond strength

The results of this study also revealed that RelyX ultimate in self-etch mode had higher bond strength values than Multilink automix self-etch resin cement. This findings may be attributed to the composition of Scotchbond universal (multi-mode adhesive) that was used with RelyX ultimate cement, it also contains 10-MDP functional acidic monomer which has been found to interact chemically with hydroxyapatite (Adhesion-decalcification concept) (25).

MDP-containing adhesives form nanolayers at the adhesive interface, on which calcium ions released up for a highly hydrolytically stable Ca-10-MDP formation which is the most stable salt compared with other salts formed from experimental acidic monomers $(26,27)$, so the high bond strength may be correlated to stable MDP-Ca salt deposition along with the strong hydrophobicity of the nanolayered structure that can protect the hybrid layer against hydrolytic bond degradation processes. Moreover, the polyalkenoic acid copolymer that also presents in Scotchbond universal adhesive increased the interaction of the adhesive with enamel as the carboxyl groups of the polyalkenoic acid dissociate to release protons in aqueous solutions enabling interacting in acid-base reactions. Carboxyl groups can replace phosphate ions of the substrate and form ionic bonds with $\mathrm{Ca}$ increasing interaction of the adhesive (28).

Bonding to dentin is more challenging due to the higher organic content, fluid pressure from dentinal tubules and the presence of a smear layer (29). In the present study the results of shear bond strength to dentin showed that RelyX ultimate in total-etch mode and Variolink II achieved better results compared to Multilink automix self-etch cement, this comes in agreement with Yin M et al (30) and Özcan M (16) who found that total-etch resin cements performed better than other self-etch and self-adhesive resin cements on dentin. These findings may be attributed to surface energy of dentin and the wettability of the resin cement on surface, asphosphoric acid removes the smear layer and increases surface roughness and thereby, the wettability of the adhesive resin (31). Interfacial morphology in this study showed deep resin tags penetrating the etched dentin surfaces as phosphoric acid opened dentinal tubules, peritubular dentin is removed, which leads to enlargement of the dentinal tubules, resulting in deeper penetration of 
the resin monomers into the exposed collagen network and mechanical interlocking with dentin with improved bonding penetration and more effective surface conditioning (32).

The relationship between resin tags and the bond strength remains a controversial issue, in the current study, numerous tags that were seen when RelyX ultimate was used in totaletch mode may be responsible for the increased bond strength values than Variolink II with fewer and longer resin tags, suggesting that the length of the resin tags did not contribute much to bond strength, this comes in agreement with Yoshiyama et al (33) who stated that the length of resin tags seems not to play an important role regarding the bond strength. According to Gwinnett (32), resin tags can contribute approximately one-third of the total shear bond strength. However, Tao and Pashley (34) reported that no link existed between the bond strength and the formation of the resin tags.

The results of the current study showed that RelyX ultimate cement had a non-significant increase in shear bond strength values when applied to dentin in the total-etch mode. Therefore, the null hypothesis that etching of dentin does not influence the bonding efficiency of multi-mode adhesive system was accepted, also the interfacial morphology showed uniform hybrid layer, numerous, well-defined and deeper resin tags compared to respective self-etch counterpart, this comes in agreement with Wagner et al (13) who found improved bond strength and penetration pattern when Scotchbond universal adhesive was applied as a total-etch on dentin. However, this finding contradicts with previous studies $(9,35)$ which revealed that etching of dentin prior to the application of self-etch adhesivesdecreased the bond strength values. They correlated this to collapse of collagen during the drying process after rinsing the etchant that lead to incomplete infiltration of the deeply demineralized collagen network by the bonding resin which has been observed as voids or micro porosity beneath and within the hybrid layer (36). This shortcoming has been overcome in Scotchbond multi-mode adhesive through the addition of low viscosity monomers like HEMA, that increase the affinity to the hydrophilic wet collagen network (13).

The results of the interfacial morphology in this study showed that Multilink automix demonstrated a better ability to remove the smear layer and create thicker hybrid layer on dentin than RelyX ultimate in self-etch mode. This finding may be attributed to the etching aggressiveness of self-etch adhesive systems as Multilink primer has $\mathrm{PH}$ of 1.9 (intermediately strong) (37), whereas Scotchbond universal adhesive has $\mathrm{PH}$ of 2.7 and considered as ultra-mild adhesive (14).

However, Multilink automix along with the intermediately strong adhesive used in this study showed lower bond strength values than RelyX ultimate in self-etch mode, this comes in agreement with other studies $(38,39)$ which revealed that higher aggressiveness of self-etch adhesives is usually not related to higher bond strengths. This finding could be correlated to presence of water in the dentinal tubules, some of the acidic monomers of the stronger selfetch adhesives retain their acidity and continue etching and result in incomplete polymerization of the subsequently applied resin (33). On the other hand, Yoshihara et al (40) found that the MDP monomer presents in the Scotchbond universal adhesive not only has the ability to chemically bond to hydroxyapatite, but also to self-assemble into nanolayers that protect the formed hybrid layer from hydrolytic degradation.

\section{CONCLUSIONS}

From this study it was concluded that:

1) An etching step prior to multi-mode adhesive resin cement significantly increased the enamel bond strength values, while for dentin there was a nonsignificantly increase in bond strength with improved penetration pattern.

2) The length of resin tags formed by total-etch adhesives seems not to play an important role in determining its bond strength.

\section{CONFLICT OF INTEREST}

The authors declare that they have no conflicts of interest

\section{REFERENCES}

1. Manhart J, Scheibenbogen-Fuchsbrunner A, Chen HY, Hickel R. A 2-year clinical study of composite and ceramic inlays. Clin Oral Invest 2000; 4:192-8.

2. Piwowarczyk A, Bender R, Ottl P, Lauer HC. Longterm bond between dual-polymerizing cementing agents and human hard dental tissue. Dent Mater 2007; 23:211-7.

3. Hikita K, Van Meerbeek B, De Munck J, Ikeda T, Van Landuyt K, Maida T, et al. Bonding effectiveness of adhesive luting agents to enamel and dentin. Dent Mater 2007; 23:71-80.

4. Fukuda R, Yoshida Y, Nakayama Y, Okazaki M, Inoue $\mathrm{S}$, Sano $\mathrm{H}$, et al. Bonding efficacy of polyalkenoic acids to hydroxyapatite of enamel and dentin. Biomaterials 2003; 24:1861-7.

5. Inoue S, Vargas MA, Abe Y, Yoshida Y, Lambrechts P, VanHerle G, et al. Microtensile bond strength of eleven contemporary adhesives to enamel. Am J Dent 2003; 16:329-34.

6. Van Meerbeek B, De Munck J, Yoshida Y, Inoue S, Vargas M, Vijay P, et al. Buonocore memorial lecture. Adhesion to enamel and dentin: current status and future challenges. Oper Dent 2003; 28:215-35.

7. Toledano M, Osório R, de Leonardi G, Rosales-Leal JI, CeballoL, Cabrerizo-Vilchez MA. Influence of selfetching primer on the resin adhesion to enamel and dentin. Am J Dent 2001; 14: 205-10.

8. Goracci C, Cury AH, Cantoro A, Papacchini F, Tay FR, Ferrari M. Microtensile bond strength and interfacial properties of self-etching and self-adhesive resin cements used to lute composite onlays under different seating forces. J Adhes Dent 2006; 8:327-35.

9. Van Landuyt KL, Kanumilli P, Munck J De, Peumans M, Lambrechts, Van Meerbeek B. Bond strength of a 
mild self-etch adhesive with and without prior acidetching. J Dent 2006; 34:77-85.

10. Taschner M, Nato F, Mazzoni A, Frankenberger R, Falconi M, Petschelt A, et al. Influence of preliminary etching on the stability of bonds created by one-step self-etch bonding systems. Euro J Oral Sci 2012; 120:239-48.

11. Erhardt MC, Osorio E, Aguilera FS, Proenca JP, Osorio $\mathrm{R}$, Toledano $\mathrm{M}$. Influence of dentin acid-etching and $\mathrm{NaOCl}$ treatment on bond strengths of self-etch adhesives. Am J Dent 2008; 21: 44-8.

12. Hanabusa M, Mine A, Kuboki T, Momoi Y, Van Ende A, Van Meerbeek B, et al. Bonding effectiveness of a new 'multimode' adhesive to enamel and dentine. J Dent 2012; 40:475-84.

13. Wagner A, Wendler M, Petschelt A, Belli R, Lohbauer U. Bonding performance of universal adhesives in different etching modes. J Dent 2014; 42: 800-7.

14. Munoz MA, Luque I, Hass V, Reis A, Loguercio AD, Bombarda NH. Immediate bonding properties of universal adhesives to dentine. J Dent 2013; 41:40411.

15. http://Www.3m.com/RelyX ultimate/technical data sheet 2013.

16. Özcan M, Mese A. Adhesion of conventional and simplified resin-based luting cements to superficial and deep dentin. Clin Oral Investig 2012; 16:1081-8.

17. Aguiar TR, Andre CB, Arrais CA, Bedran-Russo AK, Giannini M. Micromorphology of resin-dentin interfaces using self-adhesive and conventional resin cements: A confocal laser and scanning electron microscope analysis. Int. J. Adhes. 2012; 38:69-74.

18. Torii $\mathrm{Y}$, Itou $\mathrm{K}$, Hikasa $\mathrm{R}$, Iwata $\mathrm{S}$, Nishitani $\mathrm{Y}$. Enamel tensile bond strength and morphology of resinenamel interface created by acid etching system with or without moisture and self-etching priming system. J Oral Rehab 2002; 29:528-33.

19. Hashimoto M, Ohno H, Yoshida E, Hori M, Sano H, Kaga M, et al. Resin-enamel bonds made with selfetching primers on ground enamel. Eur J Oral Sci 2003; 111: 447-53.

20. Pivetta MR, Moura SK, Barroso LP, Lascala AC, Reis $\mathrm{A}$, Loguercio $\mathrm{AD}$, et al. Bond strength and etching pattern of adhesive systems to enamel: effects of conditioning time and enamel preparation. J Esthet Rest Dent 2008; 20: 322-35.

21. Pashley D, Tay F. Agressiveness of contemporary selfetching adhesives. Part 2: etching effects on unground enamel. Dent Mater 2001; 17:430-44.

22. Erickson RL, Barkmeier WW, Kimmes NS. Bond strength of self-etch adhesives to pre-etched enamel. Dent Mater 2009; 25:1187-94.

23. Li N, Nikaido T, Alireza S, Takagaki T, Chen J-H, Tagami J. Phosphoric acid-etching promotes bond strength and formation of acid-base resistant zone on enamel. Oper Dent 2012; 38:82-90.
24. Watanabe T, Tsubota K, Takamizawa T. Effect of prior acid etching on bonding durability of single-step adhesives. Oper Dent 2008;33:426-33.

25. Yoshihara K, Yoshida Y, Hayakawa S, Nagaoka N, Irie $\mathrm{M}$, Ogawa T, et al. Nano- layering of phosphoric acid ester monomer on enamel and dentin. Acta Biomater 2011;7:3187-95.

26. Yoshida Y, Yoshihara K, Nagaoka N, Hayakawa S, Torii Y, Ogawa T, et al. Self-assembled nano-layering at the adhesive interface. J Dent Res 2012; 91:376-81.

27. Van Landuyt KL, Yoshida Y, Hirata I, Snauwaert J, De Munck J, Okazaki M, et al. Influence of the chemical structure of functional monomers on their adhesive performance. J Dent Res 2008; 87:757-61.

28. Van Landuyt KL, Snauwaert J, De Munck J, Peumans M, Yoshida Y, Poitevin A, et al. Systematic review of the chemical composition of contemporary dental adhesives. Biomaterials 2007; 28:3757-85.

29. Chiba Y, Rikuta A, Yasuda G, Yamamoto A, Takamizawa H. Influence of moisture conditions on dentin bond strength of single-step self-etch adhesive systems. J Oral Sci 2006; 48: 131-7.

30. Yin M, Luo XP, Yao H, Liu X. Comparison of shear bond strength of different resin cements to ceramic and dentin. Chin J of Stomatol 2009; 44:113-6.

31. Mazzitelli C, Monticelli F, Osorio R, Casucci A, Toledano M, Ferrari M. Effect of simulated pulpal pressure on self-adhesive cements bonding to dentin. Dent Mater 2008; 24:1156-63.

32. Gwinnett AJ. Altered tissue contribution to interfacial bond strength with acid conditioned dentin. Am J Dent 1994; 7:243-6.

33. Yoshiyama M, Carvalho R, Sano H, Horner J, Brewer PD, Pashley D. Interfacial morphology and strength of bonds made to superficial versus deep dentin. Am J Dent 1995; 8:297-302.

34. Tao L, Pashley DH. Shear bond strengths to dentin: effects of surface treatments, depth and position. Dent Mater 1988; 4:371-8.

35. Sabatini C. Effect of phosphoric acid etching on the shear bond strength of two self-etch adhesives. J Appl Oral Sci 2013; 21:56-62.

36. Hashimoto M, Ohno H, Endo K, Kaga M, Sano H, Oguchi $\mathrm{H}$. The effect of hybrid layer thickness on bond strength: demineralized dentin zone of the hybrid layer. Dent Mater 2000; 16:406-11.

37. Monticelli F, Osorio R, Albaladejo A, Aguilera FS, Ferrari M, Tay FR, et al. Effects of adhesive systems and luting agents on bonding of fiber posts to root dentin. J Biomed Mater Res Part B: Appl Biomater 2006;77: 195-200.

38. Margvelashvili M, Goracci C, Beloica M, Papacchini F, Ferrari M. In vitro evaluation of bonding effectiveness to dentin of all-in-one adhesives. J Dent 2010; 38: 106-12. 
39. Kenshima S, Reis A, Uceda-Gomez N, Tancredo L, Filho LE, Nogueira FN, et al. Effect of smear layer thickness and $\mathrm{pH}$ of self-etching adhesive systems on the bond strength and gap formation to dentin. J Adhes Dent 2005; 7:117-26.

40. Yoshihara K, Yoshida Y, Nagaoka N, Fukegawa D, Hayakawa S, Mine A, et al. Nano-controlled molecular interaction at adhesive interfaces for hard tissue reconstruction. Acta Biomater 2010;6: 3573-82.

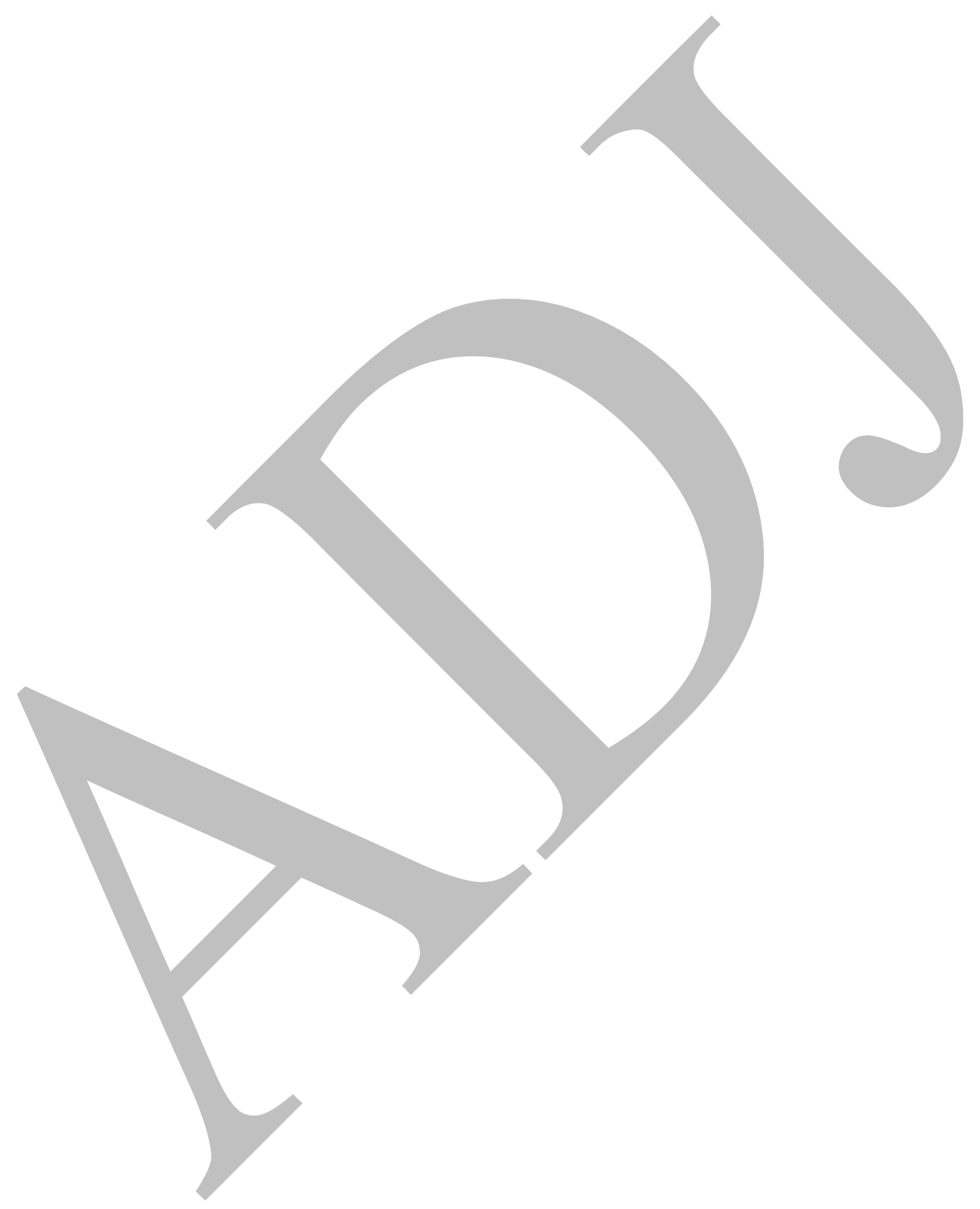

